Original Article

\title{
Evaluation of the effect of smokeless tobacco on periodontal health and oral hygiene status
}

\author{
Madhura Ramnath ${ }^{1}$, Nina Shenoy ${ }^{2}$, Reema M. Rao ${ }^{3}$, RoshniJaiswal $^{4}$ \\ ${ }^{1}$ Undergraduate student, ${ }^{2}$ Professor, ${ }^{3,4}$ Postgraduate Student, Department of Periodontics, A B Shetty M emorial Institute of \\ Dental Sciences, Derelakatte, Karnataka.
}

*Corresponding Author : Madhura Ramnath, 'Sreyas Chandra', Bilathikulam road, Vandipetta, Nadakkavu, Kozhikode - 673011 , Kerala. E-mail : shona93jr@gmail.com.

$\begin{array}{ll}\text { Received } & : 30.07 .2016 \\ \text { Review Completed } & : 02.02 .2017 \\ \text { Accepted } & : 05.02 .2017\end{array}$

Keywords : Clinical attachment loss, Gingival recession, NST-site: Non smokeless tobacco site, Smokeless tobacco keratosis, STsite: smokeless tobacco site.

\begin{tabular}{|c|}
\hline Access this article online \\
\hline Quick Response Code \\
\hline
\end{tabular}

\begin{abstract}
Background and objectives: Studies on effects of smokeless tobacco (ST) use on the periodontium are limited and have, received less attention. The aim of the present split mouth study is to evaluate the periodontal parameters and oral hygiene status of sites associated with smokeless tobacco (ST) placement and compares the corresponding parameters on the contralateral site, where smokeless tobacco is not placed (NST).
\end{abstract}

Methods: Study population: 25 subjects were selected from A.B. Shetty Memorial Institute of Dental Sciences, Deralakatte, Mangalore. Written informed consent was taken from all the participants. Oral cavity of each subject was divided into two sites Smokeless tobacco (ST) site and Non-smokeless to bacco (NST) site.

Screening examination included: Clinical examination of ST keratosis: the location, size, and specific teeth adjacent to the ST keratosis were recorded. Simplified Oral Hygiene Index (OHI-S), Gingival Index. Periodontal parameters-Probing depth (PD), Clinical attachment level, total number of teeth present in the mouth and number of teeth with attrition were recorded.

Results: Of the 25 subjects, mean OHI-Sand gingival index was 2.76 and 1.36 respectively. M ean clinical attachment level was 2.78 ( $p-\varangle .001$ ), number of teeth with recession and attrition was 3.36 and 3.04 respectively, all in favour of the ST site.

Interpretation and Conclusion: The smokeless tobacco site showed significantly greater gingival recession, attachment loss and periodontal deterioration when compared to nonsmokelesstobacco site.

\section{Introduction}

Periodontitis is an immune inflammatory disease caused by gram-negative anaerobic microorganisms characterized by destruction of soft tissue and alveolar bone. Several contributing causes for periodontal diseases are malocclusion, systemic diseases, smoking and use of smokeless tobacco though dental plaque-associated microorganisms are the primary etiologic agent. Various forms of smoking tobacco such as cigarettes, ${ }^{1,2}$ pipe, ${ }^{2,3}$ cigar, ${ }^{2,3}$ or hookah (water pipe), ${ }^{4}$ is mainly associated with periodontal tissue destruction and is a risk factor for periodontitis and loss of tooth. ${ }^{5}$ Various forms of smokeless to bacco (ST), such as loose leaf, pouch, or snuff, also possess potential periodontal health effects. ${ }^{6-8}$

Smokeless tobacco products generally consumed in India are gutka, betel quid/ paan, zardaandkhaini. Several known carcinogens, like N-nitrosonornicotine (NNN), are present in smokeless tobacco (ST), which have been confirmed to cause soft tissue alterations. Smokeless tobacco keratosis is characterized by a definite white mucosal lesion in the area of contact with the oral mucosa caused due to habitual chewing of tobacco leaves or dipping snuff and it is also called as snuff dipper's keratosis, or tobacco pouch keratosis. ${ }^{9}$ Various oral manifestations have been reported localized to the site of smokeless tobacco placement such as lesions of mucosa, ${ }^{10-12}$ recession $n^{11,13,14,16}$ and inflammation of gingiva. ${ }^{15}$

Although several oral manifestations have been associated with smokeless tobacco placement, the effect on periodontal health has not been studied in detail. 
The objectives of this study were to evaluate the periodontal changes and oral hygiene status associated with placement of habitual smokeless tobacco and to compare the periodontal changes associated with placement of habitual smokeless tobacco on one side of the arch with the contralateral site where it is not placed. This study was intended to test the hypothesis that the periodontal parameters of sites associated with smokeless tobacco (ST) placement differs from corresponding parameters of the contra lateral site (NST).

\section{Material and methods}

The study population comprised of a total of 25 subjects who were selected from A.B. Shetty Memorial Institute of Dental Sciences, Deralakatte, Mangalore. Written informed consent was taken from all the participants and ethical clearance from the institutional ethical committee was obtained prior to the study. Oral cavity of each subject was divided into two sites Smokeless tobacco (ST) site and Non-smokeless tobacco (NST). This study was conducted fromJuly-August 2014.

Materials used

- Mouth Mirror

- No.23Explorer

- Williams Graduated Periodontal Probe

Screening examination included:

Medical and dental history of the subjects were determined

\section{Clinical and Periodontal Examination}

1. ST keratosis: the location, specific teeth adjacent to the ST keratosis and size were recorded.

2. Oral Hygiene Index: Simplified ${ }^{17}$ was recorded for each subject

3. Gingival Index ${ }^{18}$ was recorded for each subject

4. Probing depth (PD): Williams Graduated Periodontal probe was used to measure to the nearest millimeter the distance from the gingival margin to the base of the periodontal pocket, at four sites of a tooth (mesial, distal, buccal and lingual).

5. Clinical attachment level and number of teeth with attrition was recorded.
Systemically healthy subjects aged between 25 to 55 years, with a minimum complement of 20 teeth, presence of clearly identifiable unilateral tobacco induced oral keratosis and individuals consuming $\geq 1$ gutka sachet/pouch daily were included in the study.

Current or known smokers, alcohol consumption, systemic diseases, any periodontal treatment in the last 6 months, history of any antibiotic /anti-inflammatory therapy for three months prior to study, pregnant and lactating women, completely edentulous patients, presence of bilateral oral smokeless tobacco keratosis, nicotine replacement therapy. Any/all of the above were excluded from the study.

\section{Statistical analysis}

The data obtained was statistically analyzed using Descriptive analysis with SPSS software version 2.0. To analyze the differences between ST - site and NST - site for the periodontal parameters and the number of teeth with recession and attrition, the Independent t-test was used.

The level of statistical significance was set at 0.05

Results

Table 1 : Study population demographics

\begin{tabular}{|l|c|c|}
\hline DEM OGRAPHICS & NO.OF SUBJECTS & PERCENTAGE (\%) \\
\hline AGE (years) & & \\
\hline 25 to 35 & 5 & 20 \\
\hline 36 to 45 & 9 & 36 \\
\hline 46 to 55 & 11 & 44 \\
\hline EDUCATON LEVEL & & \\
\hline High school & 12 & 48 \\
\hline Pre-degree & 6 & 24 \\
\hline Degree & 4 & 16 \\
\hline Higher studies & 3 & 12 \\
\hline ORAL HYGIENE & & \\
\hline Brush once daily & 14 & 56 \\
\hline Brush twice daily & 11 & 44 \\
\hline
\end{tabular}

Table 2 : Periodontal parameters

\begin{tabular}{|l|c|c|c|}
\hline PERIODONTAL PARAMETERS & $\mathbf{N}$ & MEAN & STANDARD DEVIATION \\
\hline PROBING DEPTH $($ in $\mathbf{~ m m}$ ) & 25 & 1.80 & 0.86 \\
\hline CLINICAL ATTACHM ENT & & & \\
\hline LEVEL (in mm) & 25 & 2.36 & 0.70 \\
\hline GINGIVAL INDEX & 25 & $\mathbf{1 . 3 6 *}$ & 0.50 \\
\hline ORAL HYGIENE INDEX & 25 & $\mathbf{2 . 7 6 *}$ & 0.68 \\
\hline NO. OF TEETH PRESENT & 25 & 28.68 & 2.49 \\
\hline
\end{tabular}

$*$ indicatesmoderate gingivitis

** indicates fair oral hygiene 
Figure 1 : Bar diagram depicting the questionnaire

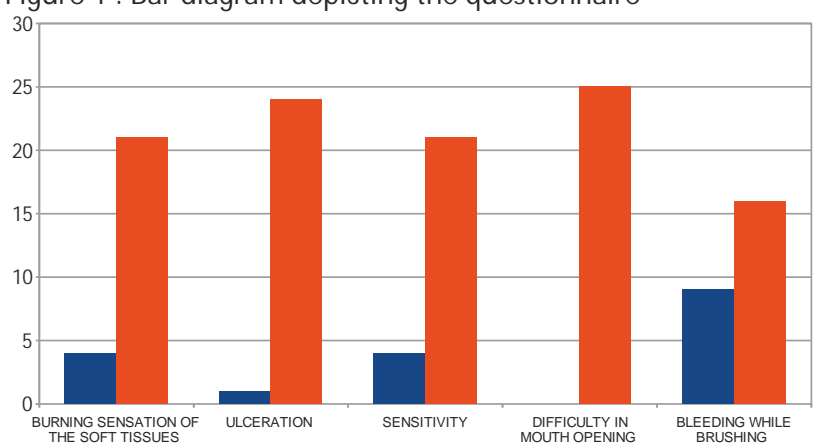

Yes

No

X-axis represents the response obtained from the participants of the study when they were subjected to the study questionnaire.

Y-axis denotes the number of subjects.

Table 3 : Periodontal parameters with comparison between ST and NST sites

\begin{tabular}{|c|c|c|c|c|c|c|}
\hline $\begin{array}{l}\text { PERIODONTAL } \\
\text { PARAMETERS } \\
\end{array}$ & & $\underline{\mathbf{N}}$ & MEAN & $\underline{\text { SD }}$ & T-VALUE & P-VALUE \\
\hline \multirow{2}{*}{$\begin{array}{l}\text { PROBING DEPTH } \\
\text { (in } \mathrm{mm} \text { ) }\end{array}$} & ST-site & 25 & 1.58 & 1.10 & 2.865 & 0.006 \\
\hline & NST-site & 25 & 0.80 & 0.79 & & \\
\hline \multirow{3}{*}{$\begin{array}{l}\text { CLINICAL } \\
\text { ATTACHM ENT } \\
\text { LEVEL( in } \mathrm{mm} \text { ) }\end{array}$} & ST-site & 25 & 2.78 & 0.86 & 3.931 & $<0.001 *$ \\
\hline & NST-site & 25 & 1.83 & 0.83 & & \\
\hline & & & & & & \\
\hline \multirow{2}{*}{$\begin{array}{l}\text { NO. OF TEETH } \\
\text { WITH RECESSION } \\
\end{array}$} & ST-site & 25 & 3.36 & 1.43 & 2.789 & 0.008 \\
\hline & NST-site & 25 & 2.20 & 1.50 & & \\
\hline NO. OF TEETH & ST-site & 25 & 3.04 & 1.51 & 2.964 & 0.005 \\
\hline WITH ATTRITION & NST-site & 25 & 1.84 & 1.34 & & \\
\hline
\end{tabular}

* indicates high statistical significance.

Other values are statistically significant.

Table 4 : Duration and number of packets of gutka use

\begin{tabular}{|l|c|c|}
\hline $\begin{array}{l}\text { NUM BER OF PACKETS OF } \\
\text { GUTKA PER DAY }\end{array}$ & FREQUENCY & PERCENT (\%) \\
\hline 1packet & 2 & 8 \\
\hline 1-5 packets & 13 & $\mathbf{5 2}$ \\
\hline M ore than 5 packets & 10 & 40 \\
\hline $\begin{array}{l}\text { NUM BER OF YEARS OF } \\
\text { GUTKA USE }\end{array}$ & FREQUENCY & PERCENT (\%) \\
\hline 1-5 years & 11 & $\mathbf{4 4}$ \\
\hline 5-10 years & 8 & 32 \\
\hline M ore than 5 years & 6 & 24 \\
\hline
\end{tabular}

Bold indicateshigher value

\section{Discussion}

Periodontal disease has multi factorial eitiology comprising of bacteria, host response and various immuno modulatory risk factors such as smoking, diabetes mellitus etc. ${ }^{19}$ Tobacco consumption and smoking is one of the most important risk factors for diseases of oral cavity including oral cancer, oral mucosal lesions and periodontitis.
Smokeless tobacco keratosis is characterized by a definite white mucosal lesion in the area of contact with the oral mucosa caused due to habitual chewing of tobacco leaves or dipping snuff and it is also called as snuff dipper's keratosis, or tobacco pouch keratosis. ${ }^{9}$

In this study, 25 subjects (smokeless tobacco users) were selected. The purpose of this study was to evaluate the oral hygiene status and periodontal parameters of sites associated with smokeless tobacco (ST) placement and compare the corresponding parameters on the contralateral sites, where smokeless tobacco is not placed (NST). Based on study questionnaire, the demographic information obtained from the subjects, the mean age of the patients was 37.8 years. $44 \%$ were between the age of $46-55 y$ rs and $48 \%$ were high school level educated. All the subjects reported daily tooth brushing, of which $56 \%$ ( $n=14)$ of the subjects brushed once daily and $44 \%(n=11)$ brushed twice daily (Table1). Out of 25 subjects, 4 subjects experienced burning sensation of the soft tissues and sensitivity while having hot or cold food items, only 1 subject had ulceration on the oral mucosa, none of the subjects had difficulty in mouth opening and 9 of the subjects had bleeding while brushing (Graph 1).

On evaluation of the periodontal parameters, it was observed that on an average subjects had a complement of 28 teeth. The gingival index and $\mathrm{OHI}-\mathrm{S}$ indicate a moderate gingivitis and fair oral hygiene despite a daily oral hygiene regimen (Table 1,2). The results of this study are similar to the study conducted by Yong $\mathrm{H}$. Chu et al using similar parameters ${ }^{20}$ However there are other studies which have reported contrary results. ${ }^{15,16}$

When the periodontal parameters were compared between ST and NST sites, (Table 3) there was greater probing depth on ST-sites. However it had no clinical relevance. Teeth located on the ST placement site had greater attachment loss ( $p \varangle 0.001$ ) which was highly significant statistically. This finding is consistent with other studies. ${ }^{19,8}$ However few studies have reported no association between ST use and clinical attachment loss, contrary to this study. ${ }^{14,16}$ Many $^{21,11}$ but not all ${ }^{22}$ clinical 
surveys on smokeless tobacco users have been reported with gingival recession. The number of teeth with recession and attrition was more on the ST side ( $p-0.008, p$ 0.005 ) respectively. This could be due to placement of tobacco in one particular site and chewing on the same side.

$52 \%$ of the subjects used 1-5 packets of gutka per day and $44 \%$ consumed the same for 1-5 years. Size of the tobacco pouch keratosis was measured (not tabulated). Since the number of subjects examined was less, a conclusive analysis relating the size of the keratosis and number and years of gutka use correlating it with the periodontal parameters could not be drawn (Table 4).

On the ST site, it was observed that larger proportion of teeth had recession. A clear causal relationship however cannot be attributed since most of the patients used a horizontal brushing technique. The recession has been hypothesized to be a result of mechanical injury either from vigorous tooth brushing at the site of its placement or from the abrasive nature of the smokeless tobacco products. ${ }^{16,23}$ The results of this study clearly indicate that the severity of periodontal destruction was more on the ST site.

A drawback of this study is lack of detailed information on the participants brushing habits especially about the type

\section{References}

1. Tomar SL, Asma S. Smoking-attributable periodontitis in the United States: findings from NHANES III. National Health and Nutrition Examination Survey.J Periodontol 2000;71(5):743-51.

2. Albandar JM, Streckfus CF, Adesanya MR, Winn DM. Cigar, pipe, and cigarette smoking as risk factors for periodontal disease and tooth loss.J Periodontol 2000;71(12):1874-81.

3. Krall EA, Garvey AJ, Gracia RI. Alveolar bone loss and tooth loss in male cigar and pipe smokers. J Am Dent Assoc 1999;130(1): 57-64.

4. Natto S, Baljoon M, Bergstrom J. Tobacco smoking and periodontal health in a Saudi Arabian population. J Periodontol 2005; 76(11): 1919-1926.

5. Borges-Yanez SA, Irigoyen-Camacho M E, M aupome G. Risk factors and prevalence of periodontitis in community-dwelling elders in M exico. J ClinPeriodontol 2006; 33(3): 184-94.

6. Dietrich T, M aserejian NN, Joshipura KJ, Krall EA, Garcia RI. Tobacco use and incidence of tooth loss among US male health professionals. J Dent Res 2007; 86(4): 373-377.

7. Bergstrom J. Tobacco smoking and risk for periodontal disease. ClinPeriodontol 2003; 30(2): 107-113.

8. Fisher MA, Taylor GW, Tilashalski KR. Smokeless tobacco and severe active periodontal disease, NHANES III. J Dent Res 2005;84(8):705710. of brush used. Hence it is difficult to evaluate whether the severity of gingival recession is due to placement of tobacco in one particular site, the type of brush used or due to vigorous and faulty tooth brushing on that site. In this study the OP patients with the habit of smokeless tobacco chewing were selected, without focus on a defined population. Selection of a definitive population of individuals such as labourers, construction workers or drivers, where this habit is more commonly observed is another limitation of this study. Further longitudinal studies need to be conducted with a definite population, type and duration of use of smokeless tobacco for better understanding in this regard. The carcinogenic potential of smokeless to bacco sites can also be studied.

\section{Conclusion}

Within the limitations of this study, the results show that there is significantly greater clinical attachment loss on ST site when compared to the NST site in smokeless tobacco users. This shows that smokeless tobacco has a possible etiological role in the development of oral lesions, and worsening of periodontal status.

Further research is needed by including more number of subjects so that a comparison between ST and NST sites stratified by the years of gutka use and the number of packets of gutka use can be done.

9. Greenberg MS, Glick M. Burket's Oral Medicine: Diagnosis and Treatment, Tenth Edition. BCDecker Inc. 2003, Page 90-91.

10. AxellT, M ornstad H, Sundstrom B. The relation of the clinical picture to the histopathology of snuff dipper's lesions in a Swedish population. J Oral Pathol 1976; 5(4): 229-236.

11. Frithiof L, AnnerothG, Lasson U, Sederholm C. The snuff-induced lesion. A clinical and morphological study of a Swedish material. ActaOdontolScand 1983; 41(1): 53-64.

12. Mornstad H, AxellT,Sundstrom B. Clinical picture of snuff dipper's lesion in Swedes. Community Dent Oral Epidemiol 1989; 17(2): $97-$ 101.

13. Christen G,M CDniel RK, Doran JE. Snuff dipping and tobacco chewing in a group of Texas college athletes. TexDent J 1979; 97: 6-10.

14. M onten U, Wennstrom JL, Ramberg P. Periodontal conditions in male adolescents using smokelesstobacco (moist snuff). J ClinPeriodontol 2006; 33(12): 863-868.

15. Poore TK, Johnson GK, Reinhardt RA, Organ CC.The effects of smokeless tobacco on clinical parameters of inflammation and gingival crevicular fluid prostaglandin E2, interleukin-1 alpha, and interleukin1 beta.J Periodontol 1995; 66(3): 177-183.

16. Robertson PB, Walsh M, Greene J, Ernster V, Grady D, Hauck W. Periodontal effects associated with the use of smokeless tobacco. 
JPeriodontol 1990; 61(7): 438-43.

17. Greene JC, Vermillion JR. The Simplified Oral Hygiene Index. J Am Dent Assoc 1964; 68:7-13.

18. Löe $H$. The Gingival Index, the Plaque Index and the Retention Index Systems.J Periodontol. 1967; 38(Suppl 6): 610-616.

19. Barbour SE, Nakashima K, ZhangJB, Tangada S, Hahn CL, Schenkein HA, Tew JG. Tobacco and smoking: environmental factors that modify the host response (immune system) and have an impact on periodontal health. Crit Rev Oral Biol M ed 1997;8(4):437-60.
20. Chu YH, Tatakis DN, Wee AG. Smokeless tobacco use and periodontal health in a rural male population. J periodontol 2010;81(6): 848-854.

21. Christen AG, McDaniel RK, Doran JE. Snuff dipping and tobacco chewing in a group of Texas college athletes. Tex Dent J 1979;97(2):610.

22. Belanger GK, Poulson TC. Smokeless tobacco: a potential health hazard for children. Pediatr Dent 1983; 5(4):266-9.

23. Christen AG. The impact of tobacco use and cessation on oral and dental diseases and conditions. AmJ M ed 1992; 93(1A): 25S-31S. 